Kenneth Kardash MD, Brian W. King PhD MD, Sanjay Datta MD

\title{
Spinal anaesthesia for Caesarean section after Harrington instrumentation
}

\begin{abstract}
A case is presented of a 33-yr-old parturient with Harrington fusion of her spine who received spinal anaesthesia with 15 mg hyperbaric bupivacaine for Caesarean delivery. Multiple attempts of needle insertion in both midline and paramedian at the $L_{3-4}$ interspace were unsuccessful, whereas the procedure was performed uneventfully at the midline of the $L_{5} S_{1}$ inters. pace. The anatomical considerations and difficulties in achieving reliable epidural anaesthesia after Harrington fusion are reviewed. Spinal anaesthesia performed at the $L_{5} S_{1}$ interspace may provide less technical difficulty and a more reliable result in such patients.
\end{abstract}

Il s'agit d'une parturiente de 33 ans déjà opérée d'une fusion vertébrale de Harrington et qui reçoit une anesthésie rachidienne avec $15 \mathrm{mg}$ de bupivacaine hyperbare pour une césarienne. Des tentatives multiples de ponction médiane et paramédiane dans l'espace $L_{3}-L_{4}$ ont échoué. Les considérations anatomiques et les difficultés pour réaliser une anesthésie épidurale fiable après une fusion de Harrington sont revues. L'anesthésie rachidienne réalisée à l'espace $L_{5}-S_{1}$ peut présenter moins de difficultés techniques et un résultat plus fiable chez de telles patientes.

Harrington first described his method of internal fixation for scoliosis $30 \mathrm{yr}$ ago. The procedure has since become

\section{Key words \\ ANAESTHESIA: obstetrical; \\ ANAESTHETIC TECHNIQUES: spinal; \\ SURGERY: orthopaedic, Harrington rods; COMPLICATIONS: scoliosis.}

From the Department of Anesthesia, Brigham and Women's Hospital, Harvard Medical School, 75 Francis Street, Boston, Massachusetts 02115.

Address correspondence to: Dr. Kenneth Kardash, Department of Anesthesia, Brigham and Women's Hospital, 75 Francis Street, Boston, MA 02115, (617) 732-7358

Telephone, (617) 277-2192 Fax.

Accepted for publication 8th April, 1993 widely implemented, particularly in young women for idiopathic scoliosis. As this generation of women approaches child-bearing age, it is not uncommon for them to present to the obstetric anaesthesia team. Indeed, the need for anaesthesia for operative delivery is even more likely in these patients than in normal parturients. '

Previous reports on this subject have focused on considerations in achieving successful epidural anaesthesia. ${ }^{2-5}$ At our institution, spinal anaesthesia is more often employed for both elective and urgent operative delivery. We describe the successful use of and advantages of this technique in a patient with Harrington fusion.

\section{Case report}

A 33-yr-old G2P1 patient presented for elective repeat Caesarean delivery at $38 \mathrm{wk}$ gestation. She had received a uneventful epidural anaesthetic for her first operative delivery. Subsequently, she had undergone Harrington rod placement and iliac bone grafting for worsening idiopathic scoliosis while in her teens. The course of her pregnancy had been uneventful. Aside from her surgical history her preoperative anaesthetic review revealed a 165 $\mathrm{cm}, 85 \mathrm{~kg}$ woman with a normal airway. Her only symptom was occasional back pain during her pregnancy. She could not recall the extent of her spinal fusion and old $x$-rays were not available. However, she had a midline back scar extending down to the level of $\mathrm{L}_{5}$ and another scar over her left iliac crest.

She consented to spinal anaesthesia after explanation of its advantages and potential difficulties. After intravenous hydration with one $\mathrm{L}$ warmed Ringer's lactate, she was placed in the right lateral decubitus position and her back was prepared aseptically. After multiple unsuccessful attempts via both the midline and paramedian approaches at the $\mathrm{L}_{3-4}$ level with a $25 \mathrm{~g}$ Whitacre needle and $21 \mathrm{~g}$ introducer, a successful dural puncture was made on the first attempt at the midline of the $\mathrm{L}_{5}-\mathrm{S}_{1}$ interspace.

Clear CSF was obtained and $15 \mathrm{mg}$ bupivacaine $0.75 \%$ in aqueous dextrose $8.25 \%$ was injected. With the patient turned immediately supine and placed in $15^{\circ}$ Trendelenburg, a $\mathrm{T}_{6}$ level of anaesthesia was obtained within 
five minutes. She was then returned to the horizontal position, and the anaesthetic level reached $T_{3}$ bilaterally over the next five minutes. Solid sensory and motor blockade were achieved. There were no changes in her vital signs and delivery proceeded uneventfully. Spinal anaesthesia resolved completely in $4.5 \mathrm{hr}$. Postoperatively she did not complain of back pain or headache and was discharged after three days.

\section{Discussion}

The anaesthetic implications of scoliosis, the most common indication for Harrington rod instrumentation, are well described ${ }^{6}$ After surgical correction, cardiorespiratory pathophysiology is usually arrested or arguably improved. ${ }^{7}$ In the setting of obstetric anaesthesia, as in this case, the primary consideration usually becomes the technical feasibility of regional anaesthesia for delivery. Certain anatomical aspects of the instrumentation are particularly relevant.

Harrington rod instrumentation is based on the principle of distracting the concave side of the scoliotic curve with a metal strut and fusing the posterior spine with bone graft. The original procedure also includes a contralateral compressing rod applied to the convex side of the curve, ${ }^{8}$ though this is now considered optional. The instrumentation itself poses little impediment to access to the spinal canal, as it is placed overlying the transverse processes. It is the healed spinal fusion, for which the rodding is merely a scaffold, that poses the problem for conducting regional anaesthesia. In preparation for the bone graft, the spinous processes are removed and the laminae are decorticated as far as the facet joints bilaterally, which are also destroyed. Hence not only are the anaesthetist's usual tactile landmarks obliterated, but attempts to penetrate to the interlaminar space may become an almost random endeavour to avoid healed bone graft.

The likelihood of successful lumbar spinal placement in these patients depends critically on the extent of the fusion. Ideally, the patient, operative records or previous radiographs can provide this information. Clinical examination can provide a rough approximation of the caudal extent of the graft if, as in our case, such information is not available. The cutaneous scar extends slightly lower beyond the fusion and spinous processes, if palpable, demonstrate an area not involved. In general, fusions for idiopathic scoliosis usually stop at $\mathrm{L}_{4}$ and should never extend to the sacrum. ${ }^{7}$ This is based on the surgical principle of preserving lumbosacral joint mobility whenever possible, and applies to all posterior spinal fusion procedures.

Rates of successful epidural placement reported in the literature have varied widely, depending on the level of fusion. In Hubbert's series of 12 patients with extensive
Harrington fusions, the epidural space was successfully located in only five (42\%), despite "multiple attempts at various interspaces with both lateral and midline approaches". ${ }^{3}$ Crosby and Halpern ${ }^{4}$ succeeded in six of eight patients (75\%), one of which required "multiple attempts." Daley et al. reported placement of an epidural catheter in all but one of 17 patients (94\%), although $29 \%$ required three or more attempts. ${ }^{5}$ Interestingly, in all of these reports failure to enter the vertebral canal occurred only if the fusion extended to $\mathrm{L}_{3}$ or lower.

Even if the epidural space is found in these patients, there is some concern about the ability of local anaesthetic to spread normally within it. ${ }^{2}$ The hooks on the ends of Harrington rods pass into or through the ligamentum flavum where they are anchored to lamina. This and the scarring from overlying bone graft may disrupt the epidural space. Indeed, although some have reported normal onset of blockade, ${ }^{2-4}$ Daley's group noted that $58 \%$ of Harrington patients had either increased local anaesthetic requirements or patchy blockade. ${ }^{5}$ Reports of dural puncture within relatively small samples by two authors ${ }^{3,4}$ is further suggestive of distorted epidural anatomy.

Considering the above problems with lumbar epidural anaesthesia in these patients, we feel the choice of subarachnoid block at the $\mathrm{L}_{5} \mathrm{~S}_{1}$ interspace offers distinct advantages. First, by utilizing the lowest available lumbar interspace the chance of avoiding spinal distortion and reaching the vertebral canal on the first attempt is maximized, particularly in cases such as ours where the caudal extent of the fusion was not definitely known. Second, the clear endpoint of CSF eliminates the equivocal identification of a possibly distorted epidural space. Third, because the intrathecal space is not directly affected by the previous surgery, the spread of local anaesthetic should be more reliable than by the epidural route. Finally, the $\mathrm{L}_{5} \mathrm{~S}_{1}$ interlaminar space is the widest in the spine, ${ }^{9}$ and least likely to be obstructed by degenerative changes that may arise secondarily to the fused joints above it.' Although we were able to pass through the space in the midline, the paramedian approach of Taylor ${ }^{9}$ would seem a useful alternative.

Although Norris has found the spread of $15 \mathrm{mg}$ hyperbaric bupivacaine injected at $\mathrm{L}_{2-3}$ or $\mathrm{L}_{3-4}$ in parturients did not correlate with their weight or height, ${ }^{10}$ we were concerned about the distribution of surgical anaesthesia when injecting at $\mathrm{L}_{5} \mathrm{~S}_{1}$. With $\mathrm{L}_{5}$ being the apex of the lumbar lordosis in normal supine patients, ${ }^{11}$ it was perhaps not necessary to employ table tilting to ensure adequate cephalad spread; but clearly such manoeuvres may prove helpful in tailoring the level of anaesthesia with hyperbaric solutions, ${ }^{12}$ and in our patient the spinal curvature had been surgically altered. In retrospect, the 
choice of a $15 \mathrm{mg}$ dose seemed appropriate in this case, but definitive dosage recommendation would have to be based on further study in a series of such patients.

While not a serious problem in this case, chronic low back pain occurs in over $40 \%$ of nonpregnant spinal fusion patients, becoming even more common with lowlevel fusions and exacerbated by pregnancy. ${ }^{1}$ In contemplating a regional anaesthetic technique, this should be borne in mind and the nature of such symptoms documented preoperatively.

The anaesthetic implications of vaginal rather than Caesarean delivery in such a patient deserves comment. The easy passage of the spinal needle at the $\mathrm{L}_{5} \mathrm{~S}_{1}$ interspace in our patient suggests that the epidural space would have been similarly accessible at this level. Indeed, if this patient had presented for a trial of labour, placement of an epidural catheter at the $\mathrm{L}_{5} \mathrm{~S}_{1}$ level would have been contemplated. Even though the previously mentioned potential difficulties in achieving adequate spread of anaesthesia might still have been encountered, we feel it would certainly have proved a much less traumatic effort than a mid-lumbar approach. A continuous spinal "microcatheter" technique using opioids and/or low concentrations of local anaesthetic would have been our first choice in this instance, but such catheters are no longer commercially available.

In considering the hypothetical disadvantage of performing dural puncture in a patient for whom subsequent epidural blood patch may prove difficult, it is interesting to note Lund's observation of "decreased incidence of post-spinal cephalgia" due to putative "postural dural relaxation" when $\mathrm{L}_{5} \mathrm{~S}_{1}$ interspace is used. ${ }^{13}$ Also, recent data suggest that our use of a pencil-point Whitacre needle results in an incidence of post-dural puncture headache at least as low as that occurring during epidural anaesthesia. ${ }^{14}$ Considering that these data do not represent experience in the post-spinal fusion setting, they may even underestimate the advantages of such needles in these technically more challenging patients.

In summary, we found that hyperbaric spinal anaesthesia via the $\mathrm{L}_{5} \mathrm{~S}_{1}$ interspace provided a reliable and less traumatic alternative to a mid-lumbar epidural in a parturient with Harrington rod instrumentation undergoing Caesarean delivery.

\section{References}

1 Cochran $T$, Irstam L, Nochenson A. Long term anatomic and functional changes in patients with adolescent idiopathic scoliosis treated by Harrington rod fusion. Spine 1983; 8: 576-84.

2 Feldstein G, Ramanathan $S$. Obstetric lumbar epidural anaesthesia in patients with previous posterior spinal fusion for kyphoscoliosis. Anesth Analg 1985; 64: 83-5.
3 Hubbert $\mathrm{CH}$. Epidural anaesthesia in patients with spinal fusion (Correspondence). Anesth Analg 1985; 64: 843.

4 Crosby ET, Halpern SH. Obstetric epidural anaesthesia in patients with Harrington instrumentation. Can $\mathbf{J}$ Anaesth 1989; 36: 693-6.

5 Daley $M D$, Robbin SM, Hew EM, Morningstar BA, Stewart JA. Epidural anaesthesia for obstetrics after spinal surgery. Reg Anesth 1990; 15: 280-4.

6 Kafer ER. Respiratory and cardiovascular function in scoliosis and the principles of anesthetic management. Anesthesiology 1970; 52: 339-51.

7 Winter RB. Posterior spinal fusion in scoliosis: indications, technique and results. Orthop Clin North Am 1979; 10: 787-800.

8 Harrington PR. Treatment of scoliosis. J Bone Joint Surg 1962; 44A: 591-610.

9 Taylor JA: Lumbosacral subarachnoid tap. J Urol 1940; 43: $561-4$.

10 Norris $M C$. Patient variables and the subarachnoid spread of hyperbaric bupivacaine in the term parturient. Anesthesiology 1990; 72: 478-82.

11 Bridenbaugh PO, Greene NM. Spinal (subarachnoid) neural blockade. In: Cousins MJ, Bridenbaugh PO (Eds.). Neural Blockade in Clinical Anesthesia and Management of Pain, Philadelphia: JB Lippencott, 1988; 215.

12 Kitahara T, Kuri S, Yoshida J. The spread of drugs used for spinal anesthesia. Anesthesiology 1956; 17: 205-8.

13 Lund PC. Principles and Practice of Spinal Anesthesia. Springfield: Charles Thomas 1971; 326-30.

14 Hurley RJ, Lambert D. Hertwig L. Post dural puncture headache in the obstetric patient: spinal vs. epidural anesthesia. Anesthesiology 1992; 77: A1018. 